Article

\title{
The Effect of Gamma Irradiation on the Physiochemical Properties of Caesium-Selective Ammonium Phosphomolybdate-Polyacrylonitrile (AMP-PAN) Composites
}

\author{
Alistair F. Holdsworth ${ }^{1}$, Harry Eccles ${ }^{2, *}$, Daniel Rowbotham ${ }^{2}$, Adam Brookfield ${ }^{1}$, \\ David Collison ${ }^{1}$, Gary Bond ${ }^{2}$, Parthiv C. Kavi ${ }^{2}$ and Ruth Edge ${ }^{3}$ (D) \\ 1 School of Chemistry, University of Manchester, Manchester M13 9PL, UK; \\ alistair.holdsworth@manchester.ac.uk (A.F.H.); adam.brookfield@manchester.ac.uk (A.B.); \\ david.collison@manchester.ac.uk (D.C.) \\ 2 School of Physical Sciences and Computing, University of Central Lancashire, Preston PR1 2HE, UK; \\ drowbotham@uclan.ac.uk (D.R.); gbond@uclan.ac.uk (G.B.); pkavi@uclan.ac.uk (P.C.K.) \\ 3 Dalton Cumbrian Facility, University of Manchester, Moor Row CA24 2HA, UK; ruth.edge@manchester.ac.uk \\ * Correspondence: heccles@uclan.ac.uk
}

Received: 7 August 2019; Accepted: 12 September 2019; Published: 19 September 2019

\begin{abstract}
Managing certain by-products of the nuclear fuel cycle, such as the radioactive isotopes of caesium: ${ }^{134} \mathrm{Cs},{ }^{135} \mathrm{Cs}$ and ${ }^{137} \mathrm{Cs}$ is challenging due to their environmental mobility and radioactivity. While a great many materials can isolate $\mathrm{Cs}+$ ions from neutral or basic aqueous solutions via ion exchange, few of these, with the exception of ammonium phosphomolybdate (AMP), function effectively in acidic media. The use of AMP, and its porous composite in polyacrylonitrile (PAN) for management of $\mathrm{Cs}$ radioisotopes in various nuclear wastes have been known for decades and are well studied, yet the effects of radiation on the physiochemical properties of such composites have only received limited attention to date. In a previous publication, we demonstrated that a 100 kGy gamma irradiation dose has negligible effect on the ion exchange performance of AMP and AMP-PAN with respect to capacity or kinetics under the Cs+ concentrations and acidity found in spent nuclear fuel (SNF) recycling. As a continuation of this prior study, in this publication we explore the effects of gamma irradiation on the physiochemical properties of AMP and AMP-PAN using a range of characterisation methods. The effects of the same gamma dose on the oxidation state of Mo in AMP and AMP-PAN, the thermal degradation of both AMP and AMP-PAN, combined with a first study into the high-temperature degradation AMP, are reported. The implications of irradiation, its possible mechanism, the conditions present in SNF recycling, and for the end-of-life disposal or recycling of these materials are also discussed.
\end{abstract}

Keywords: nuclear fuel cycle; waste management; composite materials; irradiation properties; selective separations

\section{Introduction}

In order to prevent catastrophic climate change, we must decrease our reliance on or even cease the use of fossil fuels for the generation of power and potentially other applications such as maritime shipping [1] to prevent further warming of the Earth [2]. Nuclear fission is a zero-carbon power source with the capability to completely replace fossil fuels as our electrical base load, but for sustainable increase in usage, we must reconsider the implementation of the nuclear fuel cycle to include efficient recycling of spent fuel to maximise the efficiency of finite fissile materials. Despite being carbon 
neutral, fission reactions generate a multitude of hazardous radionuclide by-products, which require careful consideration about their management [3]. Some of these, including the radioisotopes of Cs $\left({ }^{134} \mathrm{Cs}-\mathrm{t}_{1 / 2}=2.1 \mathrm{y} ;{ }^{135} \mathrm{Cs}-\mathrm{t}_{1 / 2}=2.3 \mathrm{My} ;\right.$ and $\left.{ }^{137} \mathrm{Cs} ; \mathrm{t}_{1 / 2}=30.2 \mathrm{y}\right)[3,4]$, are problematic to selectively isolate, and are environmentally mobile, [5-7] leading to concerns about their long-term storage and disposal. Of these, ${ }^{137} \mathrm{Cs}$ is of greatest concern as a strong gamma emitter, with a combined $\beta-\gamma$ thermal output of ca $70 \mathrm{~mW} / \mathrm{g}$ [8].

Many natural and synthetic materials selectively isolate and retain $\mathrm{Cs}^{+}$ions effectively from aqueous solutions, but few operate effectively at acidic $\mathrm{pH}$ values [9-15]. Ammonium phosphomolybdate (AMP, $\left.\left(\mathrm{NH}_{4}\right)_{3} \mathrm{PMo}_{12} \mathrm{O}_{40}\right)$ is an exception to this, [8,16-18] able to effectively remove even trace $\mathrm{Cs}^{+}$from decontamination liquors, [19] tank wastes, [20] and model reprocessing liquors [21,22], in the presence of high concentrations of other alkali metals $[16,17]$, or higher valence ions [21]. AMP is a dense, fine powder, often implemented as a porous composite in a polyacrylonitrile matrix (PAN) to facilitate column processing $[18,19,23]$. While both AMP and PAN are acid- and radiation-resistant, irradiation of both components has been characterised to a greater or lesser extent [24-27], and a significant volume of literature has studied the ion exchange performance of these compounds following irradiation $[18,27-30]$. The effect of radiation on their physiochemical properties is less well understood $[15,23,27]$; this is of great importance when considering the practical application of such materials in the nuclear industry. The later works of Rao et al. [28] and later Narasimharao et al [29]. in particular explored the effect of up to $200 \mathrm{MGy} \beta^{-}$irradiation on AMP, with no negative effects on ion exchange performance observed at 2 MGy exposure, though at $100 \mathrm{MGy}$ and above, the effect of radiation severely diminishes the desired action of AMP [29]. The physiochemical properties of AMP were explored in some detail in the latter of these works [29].

AMP consists of a cubic crystalline unit cell containing the Keggin phosphomolybdate $\left(\mathrm{PMo}_{12} \mathrm{O}_{40}{ }^{3-}\right.$, Figure 1) anion, surrounded by ammonium counter ions and water molecules. [31] $\mathrm{Cs}^{+}$is absorbed from aqueous solution by exchange with ammonium ions in the crystal lattice, as per Equation (1), where $0 \leq \mathrm{x} \leq 3$. Caesium phosphomolybdate $\left(\mathrm{Cs}_{3}\left[\mathrm{PMo}_{12} \mathrm{O}_{40}\right], \mathrm{CsMP}, \mathrm{x}=3\right)$ can be prepared synthetically and has been studied [32], although in ion exchange environments, only about two-thirds of the $\mathrm{NH}_{4}{ }^{+}$ ions in AMP $(\mathrm{x}=2)$ are typically replaced with $\mathrm{Cs}^{+}[17,33]$, though the theoretical capacity of AMP is $220 \mathrm{mg} / \mathrm{g}$ Cs $(\mathrm{x}=3)$.

$$
\left(\mathrm{NH}_{4}\right)_{3}\left[\mathrm{PMo}_{12} \mathrm{O}_{40}\right]_{(\mathrm{s})}+\mathrm{xCs}{ }^{+}{ }_{(\mathrm{aq})} \rightarrow\left(\mathrm{NH}_{4}\right)_{3-\mathrm{x}} \mathrm{Cs}_{\mathrm{x}}\left[\mathrm{PMo}_{12} \mathrm{O}_{40}\right]_{(\mathrm{s})}+\mathrm{xNH}_{4}{ }^{+}{ }_{(\mathrm{aq})}
$$

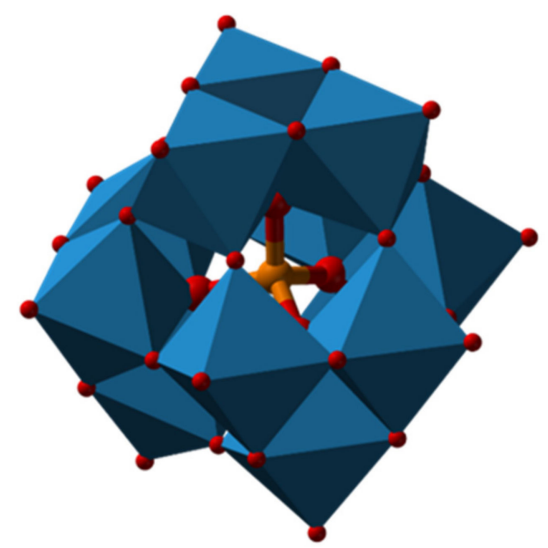

Figure 1. Keggin structure of the phosphomolybdate anion $\left(\mathrm{PMo}_{12} \mathrm{O}_{40}{ }^{3-}\right) . \mathrm{MoO}_{6}$ octahedra: blue; $\mathrm{P}$ : orange; O: red. Open source image, Wikipedia.

One of the primary challenges in spent nuclear fuel recycling is the radiolytic degradation of organic extractants caused by the decay of highly radioactive fission products and minor actinides present in spent fuel, which causes numerous operational difficulties and generates large volumes of highly radioactive liquid waste $[21,22]$. We previously proposed the use of sequential, selective 
chromatographic separations for the isolation of heat-generating radionuclides prior to the solvent extraction of fissile isotopes in spent fuel recycling to prevent this occurrence, which would reduce the prevalence of these issues and thus increase the safety and economy of the process while allowing for a reduction in the volume of high level waste (HLW) produced $[22,23,30]$, in a process we have dubbed ART: alternative reprocessing technologies. The first stage of investigation into this concept has been previously reported, and is illustrated in Figure 2. Useful radionuclides, such as Cs-137 for medical applications, could potentially be recovered this way [34], or disposed directly via encapsulation or vitrification.

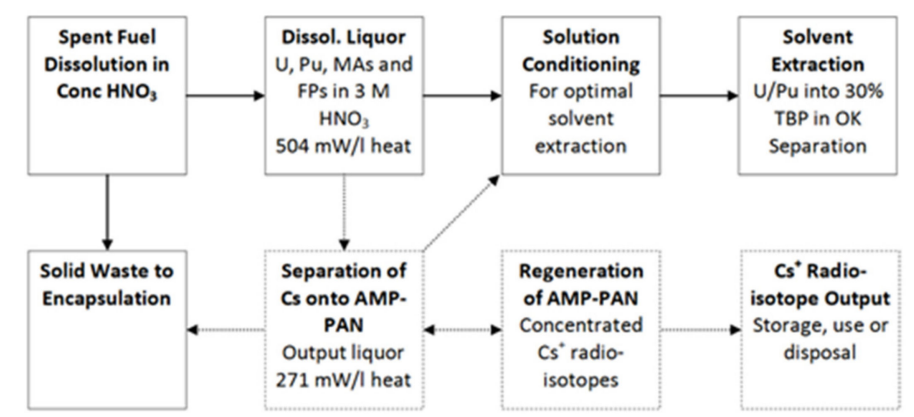

Figure 2. Simplified schematic overview of the present spent nuclear fuel (SNF) recycling (PUREX) process in solid bordered boxes. The dashed boxes represent our proposed Cs separation [21,22].

In a recent publication [30], we studied the effect of $100 \mathrm{kGy}$ of rapid (20 kGy/hr) gamma irradiation on the $\mathrm{Cs}^{+}$ion exchange performance of AMP and AMP-PAN composites under simulated spent nuclear fuel recycling conditions (with respect to $\mathrm{Cs}^{+}$concentration and acidity, based on the concept of Eccles et al.) [21], observing no reduction in capacity, kinetics, or change in uptake mechanism after irradiation. Irradiation was accompanied by a clear change in the colour of both AMP and AMP-PAN from yellow to green following irradiation, as previously reported by Sebesta and Narasimharao $[15,23,29]$ but reversible upon immersion in nitric acid [29]. This change is normally associated with the reduction of Mo from the (VI) oxidation state to (V) or lower, and suggested that physiochemical changes occurred in the samples upon irradiation. With this in mind, we explored these observations in detail via a range of analytical methods in order to expand the present base of knowledge regarding the irradiation of AMP and AMP-PAN, and to provide an initial validation of the performance of these materials under part of the conditions for their intended use. The effect of gamma irradiation on AMP-PAN composite porosity, AMP and AMP-PAN thermal degradation, and the colourimetry and redox chemistry of Mo centres in AMP is explored as this data is, to our knowledge, absent from the established literature. This publication additionally represents the first high temperature $\left(>800^{\circ} \mathrm{C}\right)$ investigation of AMP degradation, which is similarly missing from prior studies. The likely stability of AMP-PAN during the extraction of caesium from spent fuel dissolver liquor and during the interim storage when loaded with radiocaesium is also discussed, as the results presented give an insight into the implications into this proposed use of the composite in spent nuclear fuel (SNF) reprocessing.

\section{Experiments}

\subsection{Materials and AMP-PAN Composite Preparation}

Ammonium phosphomolybdate (AMP, $\left.\left(\mathrm{NH}_{4}\right)_{3} \mathrm{PMo}_{12} \mathrm{O}_{40}\right)$, polyacrylonitrile (PAN, molecular weight 80,000 ), Tween 80 , dimethyl sulfoxide (DMSO), caesium nitrate and nitric acid were obtained from Sigma, Fisher or VWR as reagent grade precursors and used as procured with no further purification required. Deionised water $(>18 \mathrm{M} \Omega / \mathrm{cm})$ was used for all experiments.

A $70 \%$ (by weight) composite of AMP contained within a porous support substrate of PAN (henceforth referred to as AMP-PAN) was prepared as described in our previous publication [30], 
using a well-established method developed by Park et al. [35], with modifications where noted [36]. An amount of $200 \mathrm{~mL}$ of DMSO was heated to $50^{\circ} \mathrm{C}$ in a water bath with overhead stirring at $250 \mathrm{rpm}$, and mixed with $0.8 \mathrm{~g}$ of Tween 80 . To this was added $28 \mathrm{~g}$ of AMP powder. The mixture was allowed to stir at $50{ }^{\circ} \mathrm{C}$ for $1 \mathrm{~h}$ to fully disperse the AMP, forming a homogenous yellow-green suspension. An amount of $12 \mathrm{~g}$ of PAN was added to this suspension over about $10 \mathrm{~min}$ and the mixture maintained at $50{ }^{\circ} \mathrm{C}$ with stirring for $6 \mathrm{~h}$ to fully dissolve the PAN. The mixture was then sprayed with compressed air into a large excess of deionised water through a confined jet nebulizer [36], (rather than dropwise addition under gravity as per Park's work) [35] forming 2-3 mm sized, spherical, porous beads of AMP-PAN. The spheres were left in the water overnight and subsequently washed 3 times with a large excess of deionised water, allowing $30 \mathrm{~min}$ for equilibration each time. The washed beads were then sieved and air dried at $60{ }^{\circ} \mathrm{C}$ for $24 \mathrm{~h}$.

\subsection{Irradiation}

Dry AMP powder and AMP-PAN were both irradiated in sealed vials, at a distance of $5 \mathrm{~cm}$ with gamma radiation (1.173 MeV and $1.333 \mathrm{MeV}$ ) to an exposure of $100 \mathrm{kGy}$ using a Foss Therapy 812 -self-shielded ${ }^{60} \mathrm{Co}$ irradiation source located at the Dalton Cumbrian Facility, Whitehaven, UK, at a rate of ca $20 \mathrm{kGy} / \mathrm{hr}$.

\subsection{Characterisation}

Optical images were recorded using a Sony Xperia XA1 equipped with an Exmor RS 23 MPixel sensor and a $24 \mathrm{~mm}$ wide-angle f2.0 lens under ambient lighting.

Powder X-Ray diffraction (XRD) was conducted using a Brucker D8 diffractometer equipped with a copper $\mathrm{K} \alpha$ radiation source and a $2^{\circ}$ multi-channel detector.

Fourier Transform Infra-Red (FTIR) analysis was conducted using a Thermo Scientific Nicolet iS5 spectrometer equipped with an ATR diamond lens, recorded in the absorption mode.

Combined thermogravimetric analysis (TGA) and differential scanning calorimetry (DSC) were conducted using a Mettler-Toledo STAR TGA/DSC 1 system under a $100 \mathrm{~cm}^{3} / \mathrm{min}$ flow of $\mathrm{N}_{2}$ from ambient temperature to $1000^{\circ} \mathrm{C}$ at a heating rate of $5^{\circ} \mathrm{C} / \mathrm{min}$.

Scanning electron microscopy (SEM) was conducted under high vacuum using an FEI Quanta 200 scanning electron microscope equipped with an EDAX Sapphire $\mathrm{Si}(\mathrm{Li})$ elemental analyser.

Solid-state ultraviolet-visual (UV-Vis) emission spectrometry and colourimetry were conducted using a Datacolour 650 and a Croma Meter CS-200 respectively. The CS-200 measurements were recorded under daylight-simulated illumination.

Surface areas were determined using the Brunauer-Emmett-Teller (BET) model at $77 \mathrm{~K}$ using nitrogen absorption (Micrometrics ASAP2020Plus), with accuracy checked against an alumina standard.

X-ray Photoelectron Spectroscopy (XPS) was performed with an Axis Ultra Hybrid spectrometer (Kratos Analytical) using monochromated Al K $\alpha$ radiation (1486.6 eV, $10 \mathrm{~mA}$ emission, $150 \mathrm{~W}$ ). Survey spectra were collected at a pass energy of $80 \mathrm{eV}$ and core level spectra at $20 \mathrm{eV}$ pass energy. A charge neutraliser was used to remove any differential charging effects at the surface, and the binding energy scale was calibrated using the $\mathrm{C} 1 \mathrm{~s}$ photoelectron peak at $284.8 \mathrm{eV}$. The base pressure of the spectrometer was $10^{-8}$ mbar.

Continuous-wave electron paramagnetic resonance (EPR) at $9 \mathrm{GHz}$ spectra of AMP and AMP-PAN were recorded using a Bruker Biospin EMX spectrometer with a Bruker ER4119HS resonator. Samples were measured for a known mass to ensure a quantitative response, with the AMP-PAN samples conducted with $1.43 \times$ the mass of AMP (as 70\% composites). AMP-PAN pellets were first ground to ensure a random orientation of the powdered samples with respect to the applied magnetic fields. 


\section{Results and Discussion}

\subsection{Chemical Changes Induced in AMP upon Irradiation}

The most apparent effect of $\gamma$ irradiation on both AMP and AMP-PAN is a clear colour change in the samples, as outlined in Figure 3. Previous researchers reported similar observations, [27-29] surmising that this was caused by reduction of the Mo(VI) centres in AMP to Mo(V), stabilised by delocalisation around the tetrahedrally-symmetrical phosphomolybdate Keggin-type ion [29]. This is normally accompanied by a "bluing" of the sample from the presence of (deep blue) Mo(V) [37], which, combined with the vibrant yellow hue of AMP, results in the green colouration observed. The yellow AMP hue a result of metal $(\mathrm{Mo})$ to ligand $(\mathrm{O})$ charge transfer, while the blue, reduced form is a result of metal-ligand and inter-species $\left(\mathrm{Mo}^{\mathrm{V}} \rightarrow \mathrm{Mo}^{\mathrm{VI}}\right)$ charge transfer [37]. This shift was recorded in solid-state visible-light spectroscopy of the samples in Figure 4, giving the absorption maxima of AMP are 566 and $552 \mathrm{~nm}$ for the virgin and irradiated material respectively; and 553 and $534 \mathrm{~nm}$ for the virgin and irradiated AMP-PAN composites, respectively. The shift of the maximum absorption wavelength to the blue end of the visible spectrum is apparent, though any resolution between blue and yellow colouration cannot be achieved using this technique. A clear reduction in absorbance towards the red end of the visible light spectrum (>530 nm) is observed for AMP, and to a lesser extent for AMP-PAN following irradiation. With respect to CIE 1931 colour space, both AMP and AMP-PAN are shown to move to greener hues upon irradiation ( $\mathrm{x}, \mathrm{y}$ for AMP: $0.431,0.484$ $\rightarrow 0.419,0.485$; AMP-PAN: $0.356,0.403 \rightarrow 0.346,0.394$, see Figure A1). $\gamma$ irradiation is known to induce yellowing in PAN [24]. Pawde et al. suggested that this effect could be exploited as an internal dosimeter, resulting from the formation of conjugated $\mathrm{C}=\mathrm{N}$ bonds and cyclisation reactions within the polymer structure, [38] though in the case of AMP-PAN, the vibrancy of AMP's hue overpowers any colour change that could be observed in the PAN matrix, though for colourless or white composites, this factor could likely be exploited in applications such as those proposed here and previously by ourselves [21,22,30]. No change is observed to the morphology or XRD powder pattern of the AMP crystallites (Figures A2 and A3 respectively) upon irradiation [28,29].

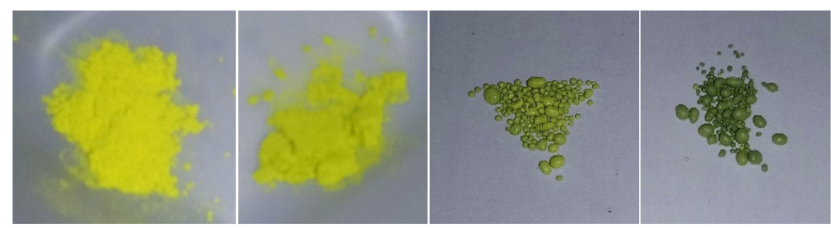

Figure 3. Optical images (L-R) of virgin AMP, irradiated AMP, virgin AMP-PAN, and irradiated AMP-PAN.

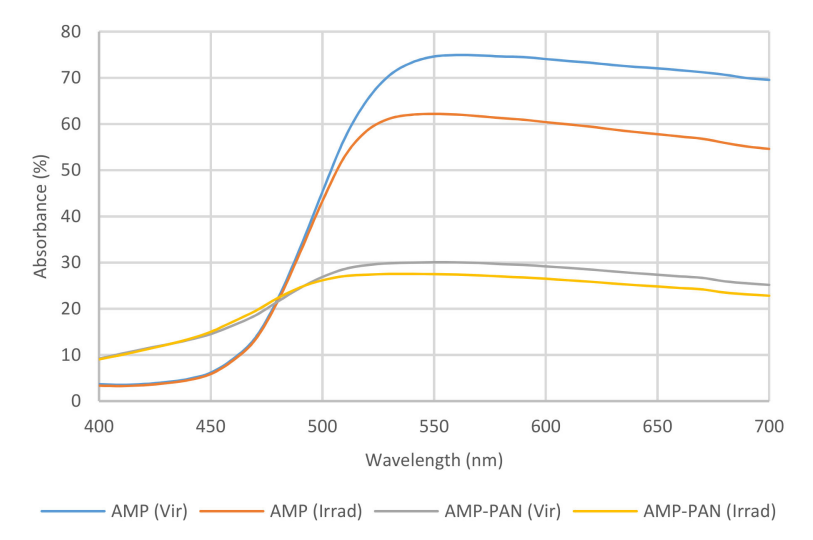

Figure 4. Visible light absorption spectra of virgin and irradiated AMP (red and blue) and AMP-PAN (green and violet). 
XPS and EPR were used to explore the oxidation state of Mo in our AMP and AMP-PAN samples before and after irradiation. The observed XPS proved to contradict the known reduction of AMP outlined above [27-29,37]. We suspect this is due to secondary electrons [39] generated in the experimental procedure effecting reduction of the virgin samples to a greater extent than the irradiated ones. EPR of $\mathrm{Mo}^{\mathrm{V}}$ centres generated a distinctive signal $(\mathrm{g}=2.7737)$ corresponding to previous literature references $[29,40]$, which increased in intensity with the redshift of the samples explored, as per Figures 4 and 5. The intensity of the baseline EPR Mo ${ }^{\mathrm{V}}$ signal increases by a factor of 3.25 for AMP upon irradiation to $100 \mathrm{kGy}$. For AMP-PAN, this is increased by a factor of 17 upon irradiation. We believe that the presence of a larger number of radiolytically labile functionalities present within the PAN polymer leads to a greater reduction of AMP in the composite compared to the pure material, for which a likely mechanism of this is reported below. The measurements are quantitative within the series measured, though due to lack of availability of a qualified internal standard, the $\mathrm{Mo}^{\mathrm{VI}}: \mathrm{Mo}^{\mathrm{V}}$ ratio in these samples cannot be defined.

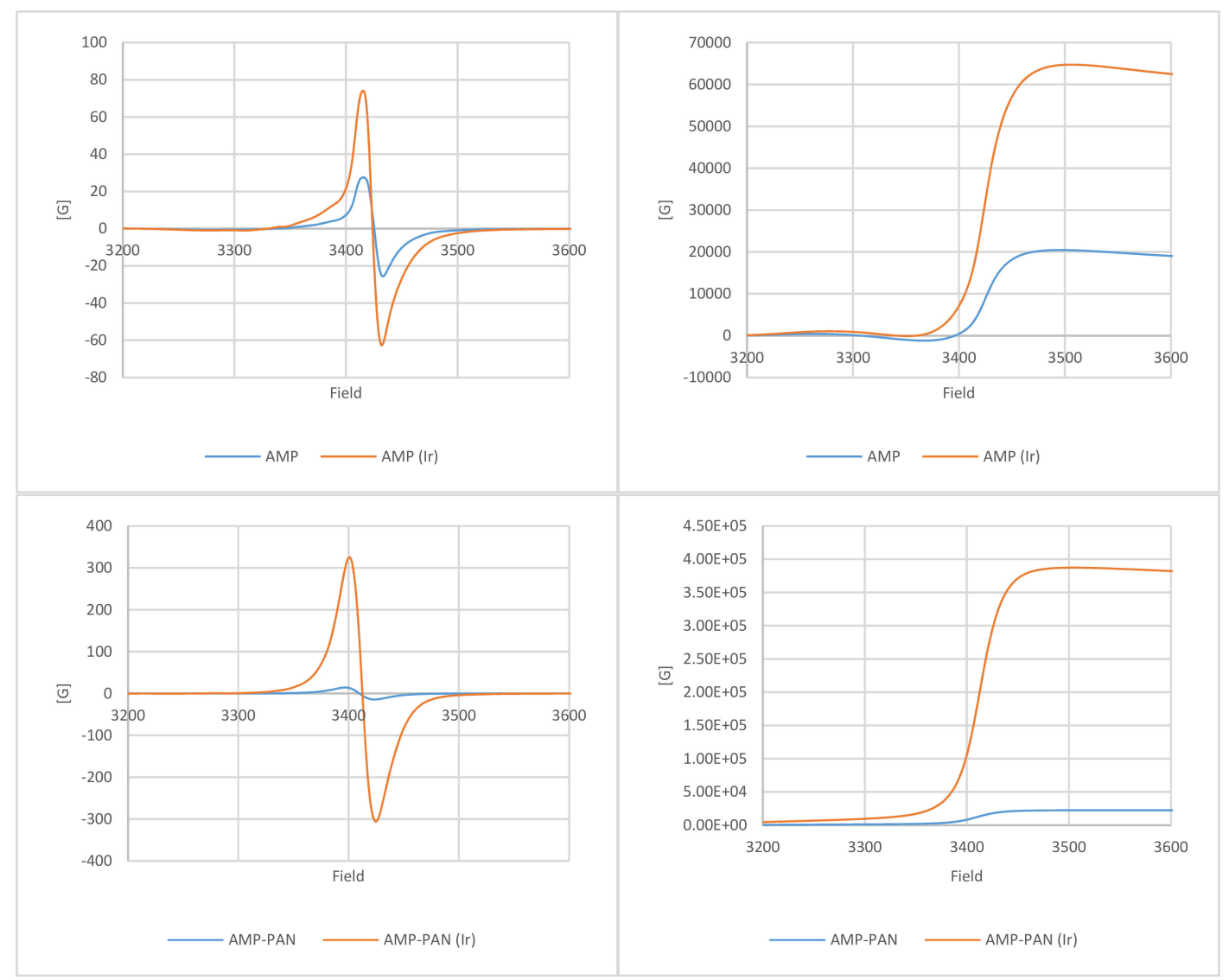

Figure 5. Recorded EPR spectra for AMP (top left) and AMP-PAN (bottom left), and 2nd integrals for AMP (top right) and AMP-PAN (bottom right). Virgin samples are blue plots, irradiated are red.

A number of possible electron sources exist within AMP capable of effecting the reductions observed. When exposed to gamma radiation, small molecules such as the water of crystallisation or the ammonium ions in AMP can photodegrade, producing a range of oxidising and reducing species via a complex network of interlinked and interdependent reactions. Radiolysis of the $\mathrm{N}-\mathrm{H}$ and $\mathrm{O}-\mathrm{H}$ bonds in these aforementioned small molecules and ions can generate $\mathrm{H}$ radicals, as per Equations (2) and (3) [41], though this is a simplification of the overall process [42]. We then surmise that these interact with the phosphomolybdate ion and effect reduction, according to Equation (4), via one of the terminal $\mathrm{M}=\mathrm{O}$ bonds [41]. As the additional negative charge of reduction is delocalised throughout the Keggin structure, the reduced phosphomolybdate ions are stable, although oxidised back to the yellow 
$\mathrm{Mo}^{\mathrm{VI}}$ form upon contact with aqueous nitric acid [29]. In catalytic environments, reduction of the phosphomolybdate ion is believed to proceed via Equation (4), which, with condensation of Mo-O-H groups at elevated temperatures, results in the dissociation of the Keggin structure [29]. Irradiation with $\beta$ particles up to 2 MGy has only limited effect on AMP, while at 200 MGy, the breakdown of the Keggin structure occurs, theorised to proceed via a phospho-heptamolybdate $\left(\mathrm{PMo}_{7} \mathrm{O}_{29}\right)$ intermediate [29].

$$
\begin{gathered}
\mathrm{NH}_{4}{ }^{+}+\gamma \rightarrow \mathrm{NH}_{3}{ }^{+}+\mathrm{H} \\
\mathrm{H}_{2} \mathrm{O}+\gamma \rightarrow \mathrm{HO}+\mathrm{H} \\
\mathrm{H}+\mathrm{Mo}^{\mathrm{VI}}=\mathrm{O} \rightarrow \mathrm{Mo}^{\mathrm{V}}-\mathrm{OH}
\end{gathered}
$$

Solid-phase FTIR spectroscopy on our virgin and irradiated AMP powders (Figure 6) indicates a radiation-induced increase in the intensity of several of the peaks present including those at 3200-3000 $\mathrm{cm}^{-1}$ (mild, O-H stretch), $1739 \mathrm{~cm}^{-1}$ (significant, unknown), $1400 \mathrm{~cm}^{-1}$ (moderate, $\mathrm{N}-\mathrm{H}$ flexural vibration), $1219 \mathrm{~cm}^{-1}$, (moderate, P-O stretch), and those associated with the Keggin phosphomolybdate anion (mild, 1068, 962, 869 and $785 \mathrm{~cm}^{-1}$ ) [29,35,43]. Zhaoyi et al. postulated that changes in the intensities of these bonds could be used to monitor the $\mathrm{Cs}^{+}$loading of AMP, though the applicability of this concept in irradiated AMP would have to be studied further [43].

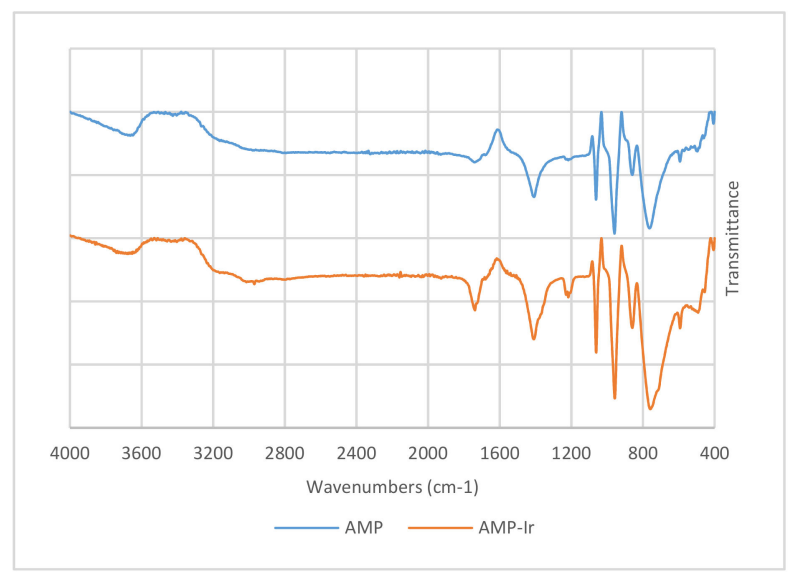

Figure 6. FTIR spectra of virgin (blue) and irradiated (red) AMP.

Previous researchers noted the $\mathrm{Cs}^{+}$capacity of AMP increases upon irradiation to 2 MGy with $\beta$ particles [29], although this was not seen in our previous work [30]. This previously reported increase in capacity could be due to the reduction of $\mathrm{Mo}^{\mathrm{VI}}=\mathrm{O}$ bonds in the AMP Keggin anion to $\mathrm{Mo}^{\mathrm{V}}-\mathrm{O}-\mathrm{H}$ bonds. If this hydroxyl functionality is suitably acidic, $\mathrm{H}^{+}$exchange for $\mathrm{Cs}^{+}$may occur. The mechanism of uptake of AMP is believed to change with increasing acidity. Narasimharao theorised that above $1 \mathrm{M} \mathrm{HNO}_{3}$, partial dissociation of AMP occurs, according to Equation (5a) (where $\mathrm{n} \leq 3$, and PM is the phosphomolybdate anion), resulting in $\mathrm{Cs}^{+}$exchange with $\mathrm{H}^{+}$instead of $\mathrm{NH}_{4}{ }^{+}$(Equations (1) and (5b) respectively) [29]. As such, any degradation of AMP caused by $\beta$ or $\gamma$ irradiation, resulting in reduction of $\mathrm{Mo}^{\mathrm{VI}}$ to $\mathrm{Mo}^{\mathrm{V}}$ or loss of $\mathrm{NH}_{3}$ and/or waters of hydration could explain the increased capacity observed to moderate (2 MGy) levels of irradiation previously reported [29], though beyond this, destruction of the Keggin ion structure would likely reduce or even remove the selectivity and/or capacity of AMP for $\mathrm{Cs}^{+}$.

$$
\begin{gathered}
\left(\mathrm{NH}_{4}\right)_{3}(\mathrm{PM})_{(\mathrm{s})}+\mathrm{nHNO}_{3(\mathrm{aq})} \rightarrow\left(\mathrm{NH}_{4}\right)_{3-\mathrm{n}} \mathrm{H}_{\mathrm{n}}(\mathrm{PM})_{\mathrm{s})}+\mathrm{nNH}_{4} \mathrm{NO}_{3(\mathrm{aq})} \\
\mathrm{H}^{+}-\mathrm{AMP}_{(\mathrm{s})}+\mathrm{Cs}^{+}{ }_{(\mathrm{aq})} \rightarrow \mathrm{Cs}^{+}-\mathrm{AMP}_{(\mathrm{s})}+\mathrm{H}^{+}{ }_{(\mathrm{aq})}
\end{gathered}
$$




\subsection{Effect or Irradiation on the Structure of the AMP-PAN Composite}

An amount of $100 \mathrm{kGy}$ of $\gamma$ irradiation has a profound effect on the porosity and internal structure of AMP-PAN composites. A clear collapse in the structure of and damage to the internal morphology of the composite is observed via SEM microscopy of bisected beads, as shown in Figure 7. This collapse in the internal structure was confirmed by the BET surface areas of the composite, which decreased from 21.56 to $7.64 \mathrm{~m}^{2} / \mathrm{g}$ upon irradiation, accompanied by an increase in average internal pore diameter from 5.24 to $13.40 \mathrm{~nm}$. Such observations have not, to our knowledge, been reported in any prior work. Despite the observed collapse in the internal structure of the polymer beads, ion exchange performance was not affected, as demonstrated in our previous publication [30]. While these results show irradiation to have a negative impact on the morphology of the composite, differing radiolytic environments, such as those encountered in aqueous $\mathrm{HNO}_{3}$ may have contrary or additional effects to those observed here, for this and other such porous composites, and thus require further investigation.

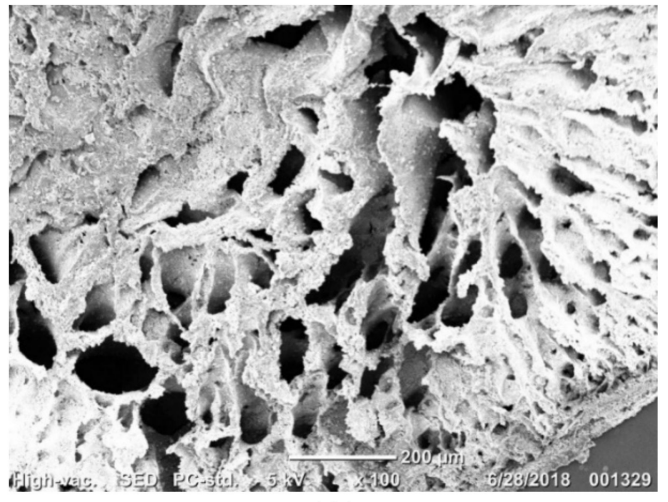

(A)

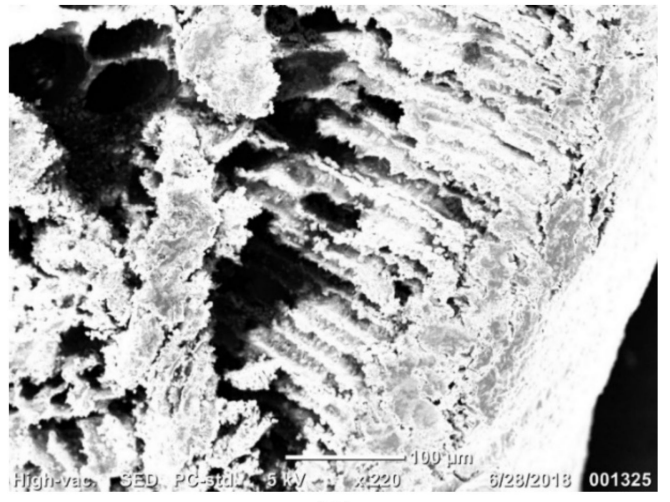

(B)

Figure 7. SEM images of virgin (A, left), and irradiated AMP-PAN (B, right) composites. These images were taken as prepared (A) and post-irradiation (B), respectively. Scale bars are 200 and $100 \mu \mathrm{m}$ for A and $\mathrm{B}$ respectively.

Solid-phase Fourier transform infra-red spectroscopy on our virgin and irradiated AMP-PAN composites (Figure 8) indicates minor reductions in the intensity of the Keggin ion peaks observed in Figure 5, and a moderate reduction in the PAN C-H stretch $\left(2912\right.$ and $\left.2971 \mathrm{~cm}^{-1}\right)$ while the PAN $-\mathrm{C} \equiv \mathrm{N}$ stretch $\left(2237 \mathrm{~cm}^{-1}\right)$ remains unaffected, and the $\mathrm{O}-\mathrm{H}$ stretch $\left(3300-3800 \mathrm{~cm}^{-1}\right)$ increases in intensity $[15,35,43,44]$. Nilchi demonstrated that similar PAN composites suffer no discernible changes to the FTIR spectrum with up to $200 \mathrm{kGy}$ of $\gamma$ irradiation [15]. The spectrum of the virgin material matches those of Park [35].

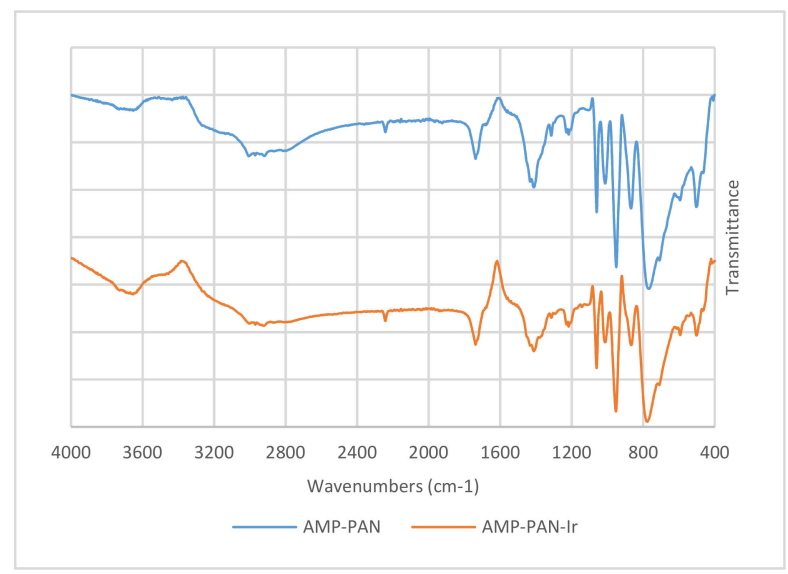

Figure 8. FTIR spectra of virgin (blue) and irradiated (red) AMP-PAN. 
The radiolytic degradation of PAN is a complex process, combining cross-linking, chain scission and gaseous evolution reactions [24,27,45]. Upon gamma irradiation to $100 \mathrm{kGy}$, these reactions change the mechanical properties of PAN: increasing crystallinity, while reducing crystallisation, melting, and onset of degradation temperatures by $20{ }^{\circ} \mathrm{C}$, and decreasing mechanical strength by $30 \%[24,45]$.

\subsection{Effect of Irradiation on the Thermal Stability of AMP and AMP-PAN}

The general physiochemical properties, in particular the thermal stability of materials for use in the nuclear industry, are of paramount importance for consideration of operational safety [28]. The thermal stability of AMP is unaffected by irradiation under $800{ }^{\circ} \mathrm{C}$ (TGA in Figure 9, DTG in Figure A4), with our results mirroring those of Ilhan et al. up to $500{ }^{\circ} \mathrm{C}$ [46]. The mass loss between 50 and $100{ }^{\circ} \mathrm{C}$ is from evaporation of bound water. From 400 to $470{ }^{\circ} \mathrm{C}$, from ammonia and water (from ammonium ions and hydroxyl groups respectively) are lost, [46] and the Keggin structure of the anion destroyed $[47,48]$. By $600{ }^{\circ} \mathrm{C}$, AMP has degraded to $\mathrm{P}_{2} \mathrm{O}_{5} \cdot 24 \mathrm{MoO}_{3}$ [46]. To our knowledge, this represents the extent of published data regarding the thermal degradation of AMP, though some researchers have investigated the thermal recovery of $\mathrm{Cs}^{+}$from AMP via volatilisation [34]. Beyond this temperature, we suspect that the volatilisation of $\mathrm{P}_{2} \mathrm{O}_{5}$ and $\mathrm{MoO}_{3}$ occurs, with virgin AMP degrading via a two-step mechanism, and the $\gamma$ irradiated sample via a three-step process, though the end product of this degradation yields the same mass, and thus, likely the same product. Similar studies have been undertaken on ammonium phosphotungstate under both air and nitrogen, but neither of these exceed the primary degradation temperature of the material $\left(>1000^{\circ} \mathrm{C}\right)$, at which point it decomposes to $\mathrm{WO}_{3}$, suggesting that phosphotungstate is more thermally stable than phosphomolybdate [49].

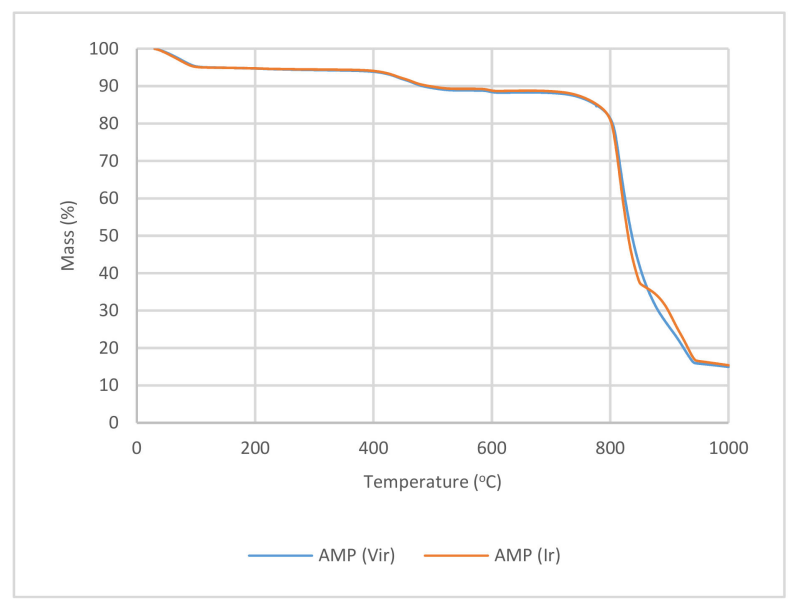

Figure 9. TGA plots of virgin (blue) and irradiated (red) AMP. $10 \mathrm{oC} / \mathrm{min}$, ambient $\rightarrow 1000{ }^{\circ} \mathrm{C}, 100$ $\mathrm{mL} / \mathrm{min} \mathrm{N} 2$.

The high temperature degradation product was simulated by calcination of AMP at $900{ }^{\circ} \mathrm{C}$ for several hours, producing a green-grey glassy solid. EDAX analysis determined the approximate elemental composition of this compound to be $\mathrm{MoO}_{3}: 0.78 \mathrm{P}_{2} \mathrm{O}_{5}$. The PXRD pattern this material is shown in Figure A5. The PXRD pattern does not correspond to any known crystallographic match.

Due to the environmental mobility of $\mathrm{Cs}^{+}$isotopes [5-7], even potentially from vitrified wasteforms [50], questions as to the best disposal route for radiocaesium-bearing materials have abounded for many years [51,52]. The vitrification of AMP as a route to Cs disposal has received very limited attention to date [34], and as such, further research will be required to assess the best disposal route of AMP-PAN composites for appropriate waste management. The implications of this are discussed in greater detail later.

The thermal stability of AMP-PAN composite beads (TGA in Figure 10, DTG in Figure A6) is far more sensitive to $\gamma$ irradiation than the active AMP ion exchange compound as a more radiolytically-sensitive organic polymer $[29,53]$. The mass loss from bound water up to $125^{\circ} \mathrm{C}$ is 
unaffected by irradiation. Above this temperature, however, the degradation of AMP-PAN is increased in the irradiated sample between $125^{\circ} \mathrm{C}$ and $350{ }^{\circ} \mathrm{C}$, during which temperature volatile species (normally $\mathrm{HCN}$ ) are lost $[54,55]$, suggesting that $\gamma$-induced damage increases the lability of these species. Until $550{ }^{\circ} \mathrm{C}$, similar degradation curves are recorded for virgin and irradiated samples, representing further loss of volatiles from PAN and the loss of $\mathrm{NH}_{3}$ and $\mathrm{H}_{2} \mathrm{O}$ from AMP (as per Figure 9). Above $600{ }^{\circ} \mathrm{C}$, the ca $20 \mathrm{wt} \%$ mass losses observed are from the volatilisation of $\mathrm{MoO}_{3}$ and $\mathrm{P}_{2} \mathrm{O}_{5}$ from AMP. The onset of this process is $755{ }^{\circ} \mathrm{C}$ for the virgin composite and $700{ }^{\circ} \mathrm{C}$ for the irradiated sample, differing from pure AMP in this respect, likely due to chemical interactions between the polymeric and inorganic components of the composite, though the quantification of these would require additional analysis of pure PAN beads and differential calculations to explore the interactions [56-58].

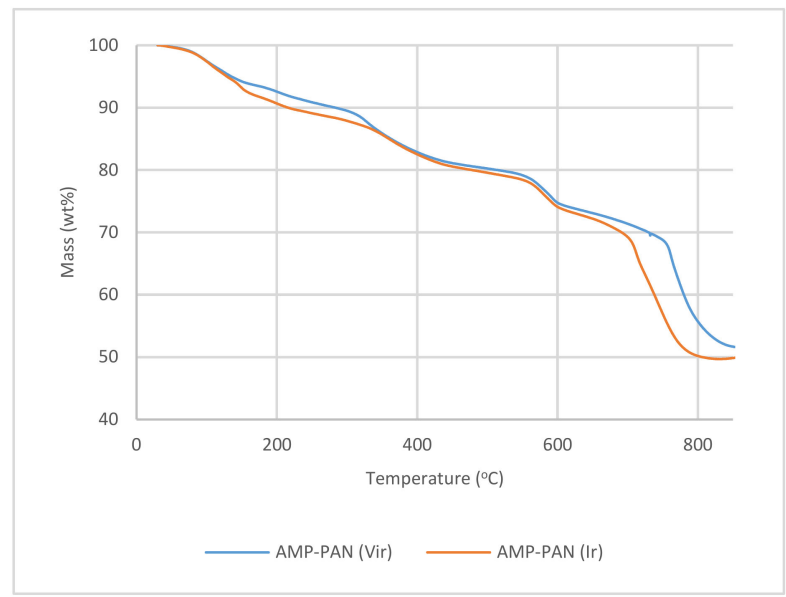

Figure 10. TGA plots of virgin (blue) and irradiated (red) AMP-PAN composite beads. $10{ }^{\circ} \mathrm{C} / \mathrm{min}$, ambient $\rightarrow 1000^{\circ} \mathrm{C}, 100 \mathrm{~mL} / \mathrm{min} \mathrm{N} 2$.

These results indicate that under the intended operational conditions for AMP (aqueous $\mathrm{HNO}_{3}$, $<100{ }^{\circ} \mathrm{C}$ ), irradiation has no negligible impact on the stability of the composite, although radiolytic aging studies conducted under these environments will also be required for comparative purposes and to gain an understanding under operational conditions. With respect to the final processing and disposal of the composite, however, the effects of radiation exposure pose a number of unresolved lines of inquiry, which will require further investigation: the possibility of utilising radiolytic aging allow for milder vitrification or post-processing of AMP-PAN for disposal; with particular attention to higher temperature degradation processes [59]; and the effects of differing irradiation environments including aqueous, and aqueous nitric acid. The former of these points is of significant importance in the final disposal of Cs-bearing AMP-PAN composites.

\subsection{Implications of Radiolysis Mechanisms}

The mechanism of radiolytic damage to materials is sensitive to the conditions used, with respect to the containing atmosphere or solution, other species present, and the type or types of ionising radiation used [60]. In this work, we conducted the gamma irradiation of AMP and AMP-PAN under sealed conditions in air, with adsorbed moisture contained with the sample. The conditions explored here, and those of the intended end-use in spent nuclear fuel recycling (the $\mathrm{HNO}_{3}-\mathrm{H}_{2} \mathrm{O}$ system), both have the potential to generate a range of both oxidising and reducing species caused by $\alpha, \beta$ and $\gamma$ radiolysis of species present. In air, oxygen and hydroxyl radicals serve as oxidisers, while, as outlined above, hydride radicals produced from water, ammonium ions, and the PAN polymer (in the case of AMP-PAN) can act as reductants, while in aqueous nitric acid, nitrous acid $\left(\mathrm{HNO}_{2}\right)$, generated through a complex series of reactions, serves as a reductant [61]. The generation of these oxidising and reducing species is proportional to the radiation dose, the reaction efficiency in generating a given species, 
also known as the G-value $[42,45,61]$, and the precursor concentration, e.g., $\left[\mathrm{HNO}_{2}\right]$ is proportional to $\left[\mathrm{HNO}_{3}\right]$ under a given radiation dose [62]. When heterogeneous species are introduced into the system, for example a solid, multi-component composite such as AMP into the $\mathrm{HNO}_{3}-\mathrm{H}_{2} \mathrm{O}$ system, the complexities increase further as the number of interactions multiply exponentially. Some research has suggested, however, that the mode of irradiation, i.e., wet or dry, leads to similar damage for the same gamma dose [60]. The possible number of irradiation conditions and other variables affecting the operational use of AMP-PAN are manifold. Further studies with active ${ }^{137} \mathrm{Cs}$, and irradiation with combinations of $\alpha, \beta$, and $\gamma$ radiation under aqueous and concentrated acidic conditions will be required to fully quantify and understand the long-term effects of use and storage on AMP-PAN beyond the scope of this initial research presented here, but are a priority target for future study.

\subsection{Considerations for Use of AMP-PAN in Spent Fuel Recycling}

As previously proposed by several of the authors, the use of sequential selective chromatography as an alternative reprocessing or recycling strategy for spent nuclear fuel (SNF), dubbed ART, could be safer, more efficient and economical, and generate lower volumes of high level waste than the existing PUREX process [21,52]. This concept is in its infancy at present, but portions of this process could be implemented into the existing PUREX flowsheet to mitigate many of the observed issues present at plants such as the former THORP and MAGNOX reprocessing plants at Sellafield, UK, the primary of which is the radiolytic degradation of organic extractants, the subsequent reactions of these with other species and undesired co-extraction of fission products with $\mathrm{U}$ and $\mathrm{Pu}$ [22]. The use of AMP-PAN to extract ${ }^{137} \mathrm{Cs}$ and other caesium radioisotopes prior to the solvent extraction of fissile elements in the PUREX process would increase the safety of the process and reduce the waste volumes produced, isolating $\mathrm{Cs}^{+}$ions and thus a significant portion of radioactivity from the acidic feed solution [22], Similar composites targeting the other heat-generating radionuclides $\left({ }^{90} \mathrm{Sr},{ }^{241} \mathrm{Am},{ }^{243} \mathrm{Cm}\right)$, and chemically problematic species ( $\mathrm{Tc}, \mathrm{Zr}$, etc.) could be added to the process as separate stages.

With this in mind, it is prudent to consider the collective $\alpha, \beta$, and $\gamma$ radiation load on composites such as AMP in both uptake and post-uptake storage conditions with respect to the radiation produced by the collective spent fuel dissolver liquor in the former case, and adsorbed $\mathrm{Cs}^{+}$ions in the latter case. Assuming the scenario of $\mathrm{UO}_{2}$ fuel with a $45 \mathrm{GWd} / \mathrm{tU}$ burnup and 8 years post-reactor cooling [22], the total heat radiative produced is $1530 \mathrm{~W} / \mathrm{tU}$. When dissolved in $\mathrm{HNO}_{3}$ to a concentration of 330 $\mathrm{g} / \mathrm{lU}$, this equates to $504.9 \mathrm{~mW} / \mathrm{L}$, of which $46.3 \%$ is generated by Cs isotopes and their daughter radionuclides. The percentage of this energy that would be absorbed by AMP-PAN in a proposed usage scenario, i.e., a stainless steel column containing the composite beads, would largely stem from $\alpha$ and $\beta$ radiation, whereas those from highly penetrating $\gamma$ rays would be more sensitive to system geometry and materials. Interactions between $\alpha$ and $\beta$ particles and the solvent system or ions in solution will also play a key part in determining the behaviour of the system, increasing the complexity of the model. From these factors, we can assume that the radiative load on AMP-PAN would be significantly less than the stated volumetric value stated above.

Once an AMP-PAN column has been filled to capacity with $\mathrm{Cs}^{+}$, it would be flushed with nitric acid to remove any unwanted ions, drained, and sealed for interim storage, or further processed for recovery of $\mathrm{Cs}^{+}$for vitrification and disposal, or for medical applications, for instance [34]. Given the theoretical capacity of AMP for $\mathrm{Cs}^{+}$ions is ca $220 \mathrm{mg} / \mathrm{g}$, this would mean a heat production, assuming a value of ca $70 \mathrm{~mW} / \mathrm{g}$ for ${ }^{137} \mathrm{Cs}$, of $10.8 \mathrm{~mW} / \mathrm{g}$ of a Cs-loaded AMP-PAN containing $70 \%$ AMP, of which $46.7 \%$ or $5.04 \mathrm{~mW} / \mathrm{g}$ is $\beta$ emission, and $53.3 \%$ or $5.76 \mathrm{~mW} / \mathrm{g}$ is $\gamma$ emission. Thus, the minimum dose a $70 \%$ AMP-PAN composite loaded to $220 \mathrm{mg} / \mathrm{g}$ with ${ }^{137} \mathrm{Cs}$ would be $5.04 \mathrm{~W} / \mathrm{kg}$, $5.04 \mathrm{~Gy} / \mathrm{s}, 302.4 \mathrm{~Gy} / \mathrm{min}$, or $18 \mathrm{kGy} / \mathrm{hr}$ [29], comparable to the rate of exposure performed in this work, assuming only the effects of $\beta$ radiation though the actual value would be higher than this when accounting for the portion of $\gamma$ absorbed, which would vary with column geometry, wall thickness, etc.

With respect to capacity, a 70\% AMP-PAN composite has a $\mathrm{Cs}^{+}$capacity of $154 \mathrm{~g} / \mathrm{kg}$, which, assuming a $\mathrm{Cs}^{+}$concentration of ca $600 \mathrm{ppm}$ in a present-day spent fuel dissolver liquor, means $1 \mathrm{~kg}$ of 
AMP-PAN could theoretically treat more than $250 \mathrm{~L}$ of spent fuel dissolver liquor, containing $84.7 \mathrm{~kg}$ of $U$ isotopes (assuming a concentration of $330 \mathrm{~g} / \mathrm{L}$ ), and thus around $12 \mathrm{~kg}$ of such an AMP-PAN composite would be required to absorb the $\mathrm{Cs}^{+}$from 1 tonne of present-day $\mathrm{UO}_{2}$-based spent fuel. Higher burnups would increase this value, due to higher concentrations of Cs fission products, while other process factors could increase or decrease the requirement accordingly. The yield of Cs radioisotopes remains largely constant regardless of fission source $\left({ }^{233} \mathrm{U},{ }^{235} \mathrm{U},{ }^{239} \mathrm{Pu}\right.$, etc) [63].

\section{Conclusions}

In this publication, we have undertaken a preliminary investigation into the effects of a $100 \mathrm{kGy}$ dose of $\gamma$ radiation on the physiochemical properties of Cs-selective AMP and AMP-PAN ion exchange composites. While previous researchers have proposed the use of AMP-PAN for isolation of Cs radioisotopes from PUREX raffinate post-extraction of the valuable fissile materials $[19,28]$, we believe our previous and continuing work, including this research, is the first to propose and assess the potential of ion exchange in spent-fuel recycling for more efficient, safe, and economical with holistic waste management [21,22,30].

From this and our other initial studies, we can ascertain that AMP-PAN possesses suitable radiation resistance to be of promise for our intended application, although further research remains to be undertaken to fully assess the implications of radiolysis with combined $\alpha, \beta$, and $\gamma$ systems; the effects of acidity; and the disposal, vitrification, or recycling routes before implementation. While technologically we believe the use of AMP-PAN for selective Cs isolation in next-generation spent fuel recycling plants is feasible within minimal further development, regulatory hurdles remain the largest barrier to adoption of such a system commercially.

Author Contributions: Conceptualization, A.F.H., H.E., and G.B.; methodology, A.F.H., H.E., D.C., and R.E.; validation, A.F.H., H.E., D.R., A.B., P.C.K., and R.E.; formal analysis, A.F.H., H.E., A.B., and D.C.; investigation, A.F.H., D.R., A.B., P.C.K., and R.E.; resources, A.F.H., H.E., D.C., and R.E.; writing-original draft preparation, A.F.H. and H.E.; writing-review and editing, A.F.H. and H.E.; visualization, A.F.H.; supervision, H.E.; project administration, A.F.H. and H.E.; funding acquisition, H.E. and G.B.

Funding: This research was funded by EPSRC, UK, grant number EP/LO18616/1. The APC was funded by the EPSRC.

Acknowledgments: We wish to thank Huw Owens for his generous help with the colourimetry experiments and interpretation, Chris Muryn and Ben Spencer for their generous assistance with the XPS experiments and interpretation, and to M. A. Denecke for her valued contributions.

Conflicts of Interest: The authors declare no conflict of interest. The funders had no role in the design of the study; in the collection, analyses, or interpretation of data; in the writing of the manuscript, or in the decision to publish the results.

\section{Appendix A}

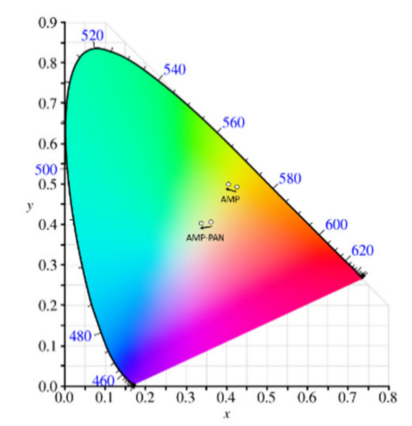

Figure A1. Movement of AMP and AMP-PAN in colour space upon irradiation. $\mathrm{X}$ and $\mathrm{Y}$ are the coordinates within the CIE colour space. 


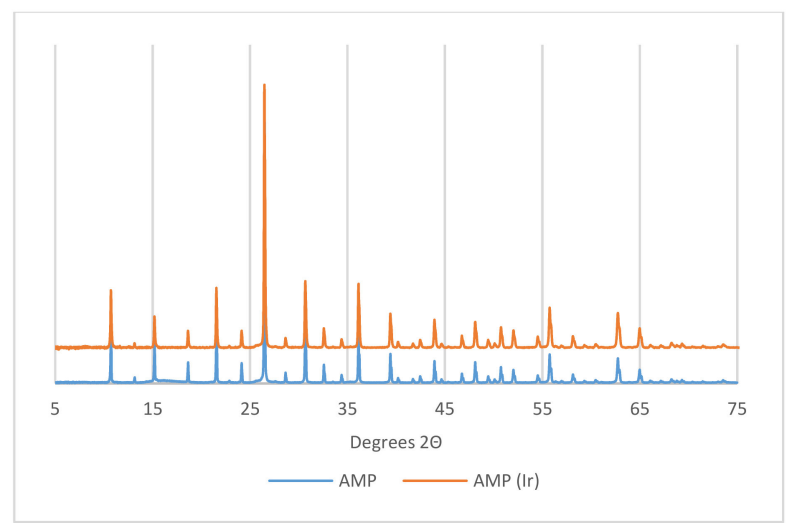

Figure A2. PXRDs of virgin (blue) and irradiated (red) AMP.

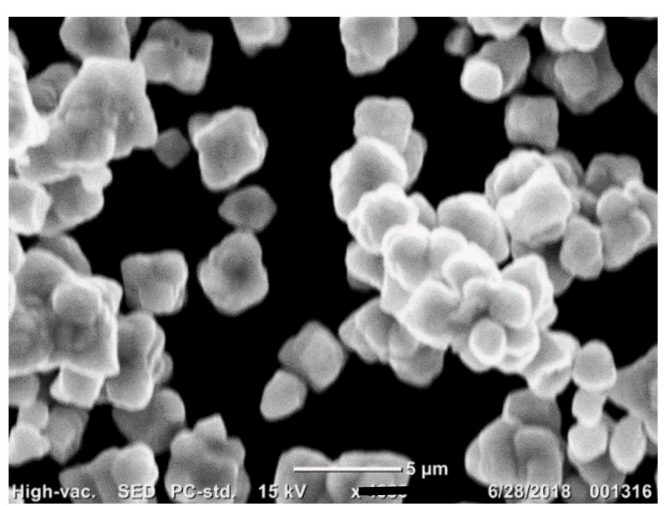

(A)

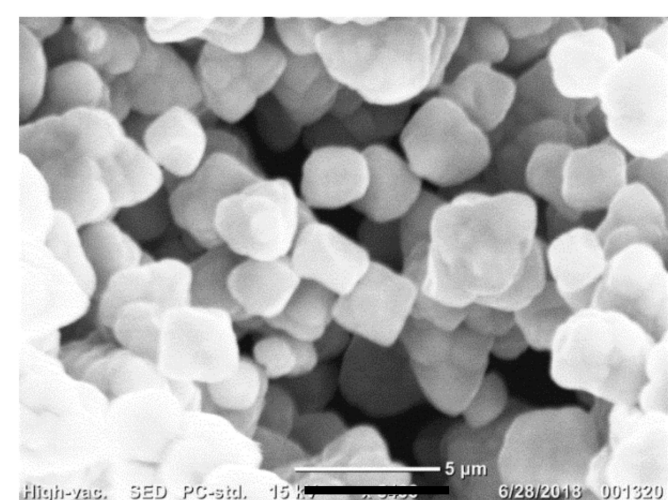

(B)

Figure A3. SEM images of virgin (A) and irradiated AMP (B). Scale bars $5 \mu \mathrm{m}$ for both figures.

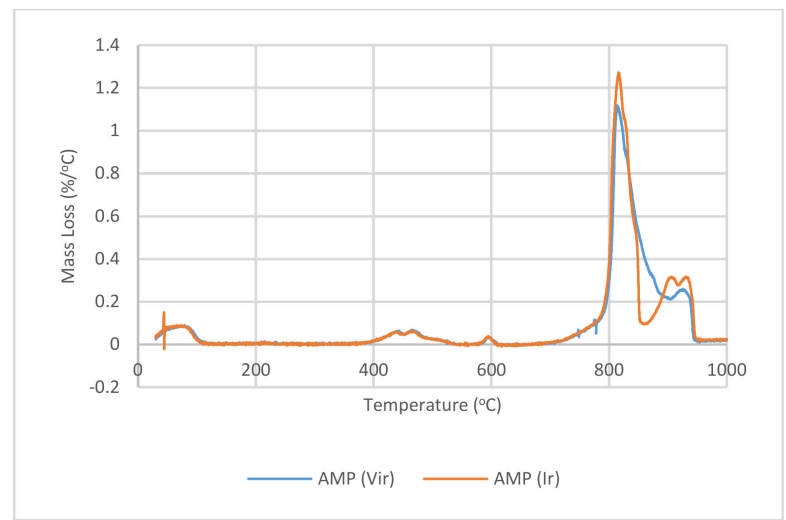

Figure A4. TGA rates of mass loss of virgin (blue) and irradiated (orange) AMP-PAN. $10{ }^{\circ} \mathrm{C} / \mathrm{min}$, $100 \mathrm{~mL} / \mathrm{min} \mathrm{N}_{2}$. 


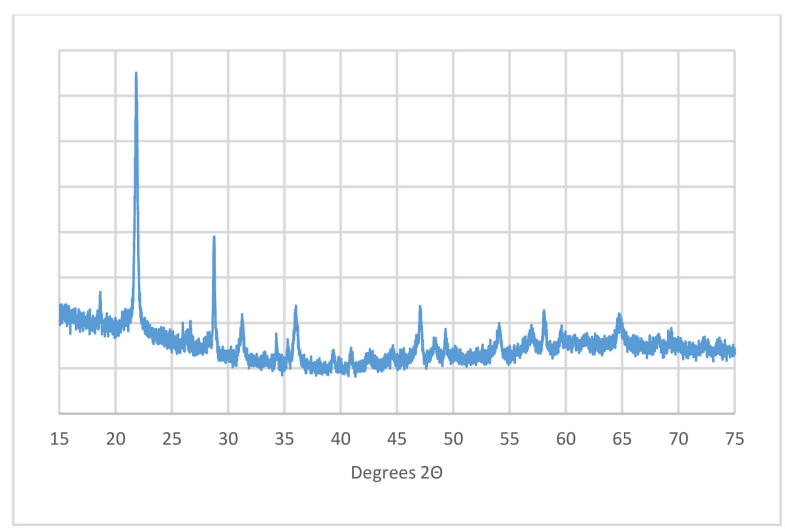

Figure A5. XRD pattern of AMP calcination product.

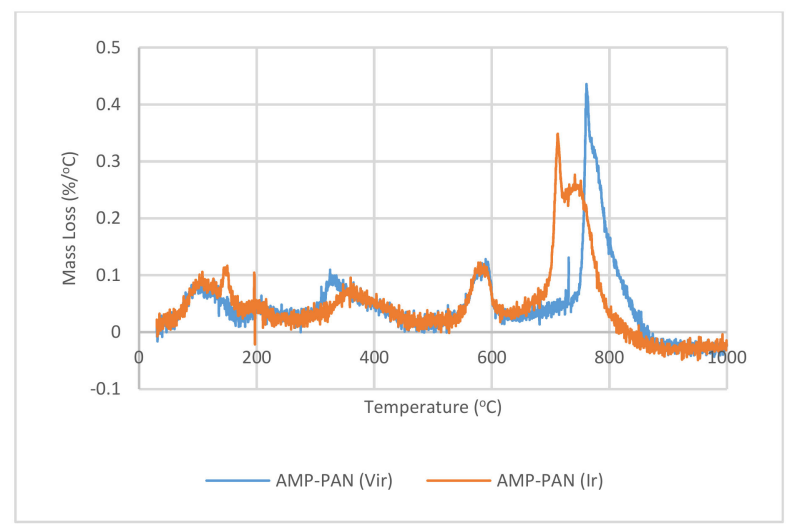

Figure A6. TGA rates of mass loss of virgin (blue) and irradiated (red) AMP-PAN. $10{ }^{\circ} \mathrm{C} / \mathrm{min}$, $100 \mathrm{~mL} / \mathrm{min} \mathrm{N}_{2}$.

\section{References}

1. Carlton, J.S.; Smart, R.; Jenkins, V. The nuclear propulsion of merchant ships: Aspects of engineering, science and technology. J. Mar. Eng. Technol. 2011, 10, 47-59. [CrossRef]

2. Tavoni, M.; van der Zwaan, B. Nuclear Versus Coal plus CCS: A Comparison of Two Competitive Base-Load Climate Control Options. Environ. Model. Assess. 2011, 16, 431-440. [CrossRef]

3. National Research Council. Nuclear Wastes: Technologies for Separations and Transmutation; National Academy Press: Washington, DC, USA, 1996. [CrossRef]

4. Aoyama, M. Evidence of stratospheric fallout of caesium isotopes from the Chernobyl accident. Geophys. Res. Let. 1988, 15, 327-330. [CrossRef]

5. Livens, F.R.; Loveland, P.J. The influence of soil properties on the environmental mobility of caesium in Cumbria. Soil Use Manag. 1988, 4, 69-75. [CrossRef]

6. Maguire, S.; Pulford, I.D.; Cook, G.T.; Mackenzie, A.B. Caesium sorption-Desorption in clay-Humic acid systems. J. Soil Sci. 1992, 43, 689-696. [CrossRef]

7. Desmet, G.M.; van Loon, L.R.; Howard, B.J. Chemical speciation and bioavailability of elements in the environment and their relevance to radioecology. Sci. Tot. Environ. 1991, 100, 105-124. [CrossRef]

8. Mahendra, C.; Satya Sai, P.M.; Babu, C.A.; Revathy, K.; Rajan, K.K. Analysis and modeling of fixed bed sorption of cesium by AMP-PAN. J. Environ. Chem. Eng. 2015, 3, 1546-1554. [CrossRef]

9. Dyer, A.; Pillinger, M.; Amin, S. Ion exchange of caesium and strontium on a titanosilicate analogue of the mineral pharmacosiderite. J. Mater. Chem. 1999, 9, 2481-2487. [CrossRef]

10. Vlasselaer, S.; D'Olieslager, W.; D'Hont, M. Caesium ion exchange equilibrium on potassium-zinc-hexacyanoferrate(II), $\mathrm{K} 2 \mathrm{Zn} 3[\mathrm{Fe}(\mathrm{CN}) 6] 2$. Selectivity for alkali ions. J. Radioanal. Chem. 1977, 35, 211-222. [CrossRef]

11. Amphlet, C.B.; McDonald, L.A. Equilibrium studies on natural ion-exchange minerals-I. Caesium and strontium. J. Inorg. Nucl. Chem. 1956, 2, 403-414. [CrossRef] 
12. Alberti, G.; Costantino, U.; Allulli, S.; Massucci, M.A. Crystalline insoluble acid salts of tetravalent metals-XX Forward and reverse $\mathrm{Cs}+\mathrm{H}+$ and $\mathrm{Rb}+/ \mathrm{H}+$ ion exchange on crystalline zirconium phosphate. J. Inorg. Nucl. Chem. 1975, 37, 1779-1786. [CrossRef]

13. Valsalaer, T.P.; Roy, S.C.; Shah, J.G.; Gabriel, J.; Raj, K.; Venugopal, V. Removal of radioactive caesium from low level radioactive waste (LLW) streams using cobalt ferrocyanide impregnated organic anion exchanger. J. Haz. Mater. 2009, 166, 1148-1153. [CrossRef]

14. Saberi, R.; Nilchi, A.; Garmarodi, S.R.; Zarghami, R. Adsorption characteristic of 137Cs from aqueous solution using PAN-based sodium titanosilicate composite. J. Radioanal. Nucl. Chem. 2010, 284, 461-469. [CrossRef]

15. Nilchi, A.; Saberi, R.; Garmarodi, S.R.; Bagheri, A. Evaluation of PAN-based manganese dioxide composite for the sorptive removal of cesium-137 from aqueous solutions. Appl. Radiat. Isotop. 2012, 70, 369-374. [CrossRef]

16. Smit, J.V.R.; Jacobs, J.J.; Robb, W. Cation exchange properties of the ammonium heteropolyacid salts. J. Inorg. Nucl. Chem. 1959, 12, 95-103. [CrossRef]

17. Smit, J.V.R.; Jacobs, J.J.; Robb, W. Cation exchange on ammonium molybdophosphate-I: The alkali metals. J. Inorg. Nucl. Chem. 1959, 12, 104-112. [CrossRef]

18. Sebesta, F.; Stefula, V. Composite ion exchanger with ammonium molybdophosphate and its properties. J. Radioanal. Nucl. Chem. 1990, 140. [CrossRef]

19. Tranter, T.J.; Herbst, R.S.; Todd, T.A.; Olson, A.L.; Eldredge, H.B. Evaluation of ammonium molybdophosphate-polyacrylonitrile (AMP-PAN) as a cesium selective sorbent for the removal of 137 Cs from acidic nuclear waste solutions. Adv. Environ. Res. 2002, 6, 107-121. [CrossRef]

20. Todd, T.A.; Mann, N.R.; Tranter, T.J.; Sebesta, F.; John, J.; Motl, A. Cesium sorption from concentrated acidic tank wastes using ammonium molybdophosphate-polyacrylonitrile composite sorbents. J. Radioanal. Nucl. Chem. 2002, 254, 47-52. [CrossRef]

21. Eccles, H.; Emmott, J.D.; Bond, G. Advanced Reprocessing-The Potential for Continuous Chromatographic Separations. J. Chromatog. Sep. Tech. 2017, 8, 348. [CrossRef]

22. Bond, G.; Eccles, H.; Kavi, P.C.; Holdsworth, A.F.; Rowbotham, D.; Mao, R. Removal of Cesium from Simulated Spent Fuel Dissolver Liquor. J. Chromatog. Separ. Tech. 2019, 10, 417. [CrossRef]

23. Ding, D. Removal of Cesium from Aqueous Solution by Using Newly Developed Adsorbents and Comparative Study. Ph.D. Thesis, University of Tsukuba, Tsukuba, Japan, April 2014.

24. Pawde, S.M.; Deskmukh, K. Influence of $\gamma$ irradiation on the properties of polyacrylonitrile films. J. Appl. Polym. Sci. 2008, 2569-2578. [CrossRef]

25. Papaconstantinou, E.; Hoffman, M.Z. One-Electron Reduction of 18-Molybdodiphosphate and 18-Tungstodiphosphate Ions in Aqueous Solution. A Pulse Radiolysis Study. Inorg. Chem. 1982, 21, 2087-2089. [CrossRef]

26. Troupis, A.; Hiskia, A.; Papaconstantinou, E. Synthesis of Metal Nanoparticles by Using Polyoxometalates as Photocatalysts and Stabilizers. Angew. Chem. Int. Ed. 2002, 41, 1911-1914. [CrossRef]

27. Sebesta, F.; John, J.; Motl, A.; Stamberg, K. Evaluation of Polyacrylonitrile (PAN) as a Binding Polymer for Absorbers Used to Treat Liquid Radioactive Wastes; Report SAND-95-2729; Sandia National Labs: Livermore, CA, USA, 1995. [CrossRef]

28. Rao, K.L.N.; Mathew, C.; Deshpande, R.S.; Jadhav, A.V.; Pande, B.M.; Shulka, J.P. Effects of electron beam irradiation on inorganic exchanger AMP. Radiat. Phys. Chem. 1997, 49, 85-87. [CrossRef]

29. Narasimharao, K.L.; Sarma, K.S.; Mathew, C.; Jadhav, A.V.; Shulka, J.P.; Natarajan, V.; Seshagiri, T.K.; Sali, S.K.; Dhiwar, V.I.; Pande, B.; et al. Physico-chemical and ion exchange characteristics of ammonium molybdophosphate irradiated with electrons. J. Chem. Soc. Faraday Trans. 1998, 94, 1641-1647. [CrossRef]

30. Holdsworth, A.F.; Eccles, H.; Rowbotham, D.; Bond, G.; Kavi, P.C.; Edge, R. The Effect of Gamma Irradiation on the Ion Exchange Properties of Caesium-Selective Ammonium Phosphomolybdate-Polyacrylonitrile (AMP-PAN) Composites under Spent Fuel Recycling Conditions. Separations 2019, 6, 23. [CrossRef]

31. Bykhovskii, D.N.; Kol'tsova, T.I.; Kuz'mina, M.A. Phases of variable composition in crystallization of cesium phosphomolybdate. Radiochemistry 2006, 48, 429-433. [CrossRef]

32. Broadbank, R.W.C.; Dhabanandana, S.; Harding, R.D. A possible use of ammonium 12-molybdophosphate for assaying certain radioactive fission products in water. Analyst 1960, 85, 365-370. [CrossRef] 
33. Paul, N.; Hammond, R.B.; Hunter, T.N.; Edmondson, M.; Maxwell, L.; Biggs, S. Synthesis of nuclear waste simulants by reaction precipitation: Formation of caesium phosphomolybdate, zirconium molybdate and morphology modification with citratomolybdate complex. Polyhedron 2015, 89, 129-141. [CrossRef]

34. Dash, A.; Varma, R.N.; Ram, R.; Saxena, S.K.; Mathakar, A.R.; Avhad, B.G.; Sastry, K.V.S.; Sangurdekar, P.R.; Venkatesh, M. Fabrication of Cesium-137 Brachytherapy Sources Using Vitrification Technology. Canc. Biother. Radiopharm. 2009, 24, 489-502. [CrossRef] [PubMed]

35. Park, Y.; Lee, Y.C.; Shin, W.S.; Choi, S.J. Removal of cobalt, strontium and cesium from radioactive laundry wastewater by ammonium molybdophosphate-polyacrylonitrile (AMP-PAN). Chem. Eng. J. 2010, 162, 685-695. [CrossRef]

36. Moon, J.-K.; Kim, K.-W.; Jung, C.-H.; Shui, Y.-G.; Lee, E.-H. Preparation of Organic-Inorganic Composite Adsorbent Beads for Removal of Radionuclides and Heavy Metal Ions. J. Radioanal. Nucl. Chem. 2000, 246, 299-307. [CrossRef]

37. Travaglini, G.; Wachter, P.; Marcus, J.; Schlenker, C. The blue bronze K0.3MoO3: A new one-dimensional conductor. Solid State Comm. 1981, 37, 599-603. [CrossRef]

38. Grassie, N.; Hay, J.N. Thermal coloration and insolubilization in polyacrylonitrile. J. Polym. Sci. 1962, 56, 163, 189-202. [CrossRef]

39. Aguilera, L.; Montero, I.; Davila, M.E.; Ruiz, A.; Galan, L.; Nistor, V.; Raboso, D.; Palomares, J.; Soria, F. CuO nanowires for inhibiting secondary electron emission. J. Phys. D Appl. Phys. 2013, 46, 165104. [CrossRef]

40. Gonzalez, P.J.; Rivas, M.G.; Brondino, C.D.; Bursakov, S.A.; Moura, I.; Moura, J.J.G. EPR and redox properties of periplasmic nitrate reductase from Desulfovibrio desulfuricans ATCC 27774. J. Biol. Inorg. Chem. 2006, 11, 609-616. [CrossRef]

41. Pascaru, I.; Constantinescu, O.; Constantinescu, M.; Arizan, O.J. L'étude des centres paramagnétiques produits dans le Mo 7 O 24 (NH 4 ) 6.4H 2 O polycristallin irradié. Chim. Phys. 1965, 62, 1283.

42. Gehringer, P. IAEA Lecture-Application of Electron Beams in Industry and Environmental Protection. In Proceedings of the IAEA's Interregional Training Course on Developments in the Application of Electron Beams in Industry and Environmental Protection, Warsaw, Poland, 6-17 October 1997.

43. Zhaoyi, T.; Zhaoya, H.; Dong, Z.; Xiaolin, W. Structural characterization of ammonium molybdophosphate with different amount of cesium adsorption. J. Radioanal. Nucl. Chem. 2014, 299, 1165-1169. [CrossRef]

44. Coleman, M.M.; Sivy, G.T. Polymer Characterization; Craver, C.D., Ed.; ACS: Washington, DC, USA, 1983; pp. 559-570.

45. Liu, W.; Wang, M.; Xing, Z.; Wu, G. The free radical species in polyacrylonitrile fibers induced by $\gamma$-radiation and their decay behaviors. Radiat. Phys. Chem. 2012, 81, 835-839. [CrossRef]

46. Ilhan, S.; Kahruman, C.; Yusufoglu, I. Characterization of the thermal decomposition products of ammonium phosphomolybdate hydrate. J. Anal. Appl. Pyrol. 2007, 78, 363-370. [CrossRef]

47. Misono, M. Heterogeneous Catalysis by Heteropoly Compounds of Molybdenum and Tungsten. Catal. Rev. Sci. Eng. 1987, 29, 269-321. [CrossRef]

48. Tsigdinos, G.A. Heteropoly compounds of molybdenum and tungsten. Top. Curr. Chem. 1977, 76, 1-64. [CrossRef]

49. Ilhan, S.; Kalpakli, A.O.; Kahruman, C.; Yusufoglu, I. The investigation of thermal decomposition mechanism of ammonium phosphotungstate hydrate in inert gas atmosphere. Thermochim. Acta 2012, 546, 1-7. [CrossRef]

50. Borkel, C. Understanding the Mobility of Caesium, Nickel and Selenium Released from Waste Disposal: Chemical Retention Mechanisms of Degraded Cement. Ph.D. Thesis, Polytechnic University of Catalonia, Barcelona, Spain, 11 November 2015.

51. Tranter, T.J.; Vereshchagina, T.A.; Utgikar, V. An Inorganic Microsphere Composite for the Selective Removal of 137Cesium from Acidic Nuclear Waste Solutions. 1: Equilibrium Capacity and Kinetic Properties of the Sorbent. Solv. Extr. Ion Exch. 2009, 27, 199-218. [CrossRef]

52. Horowitz, E.P.; Dietz, M.L.; Diamond, H.; Rogers, R.D.; Leonard, R.A. Advanced chemical separations in support of the clean option strategy. Global ‘93-Future Nuclear Systems: Emerging Fuel Cycles and Waste Disposal Options, Seattle, WA, USA, 12-17 September 1993.

53. Egorov, E.V.; Novikov, P.D. Action of Ionizing Radiation on Ion Exchange Materials; Israel Program for Scientific Translations: Jerusalem, Israel, 1967; pp. 74-77.

54. Zhao, W.; Yamamoto, Y.; Tagawa, S. Regulation of the Thermal Reactions of Polyacrylonitrile by $\gamma$-Irradiation. Chem. Mater. 1999, 11, 1030-1034. [CrossRef] 
55. Xue, T.J.; McKinney, M.A.; Wilkie, C.A. The thermal degradation of polyacrylonitrile. Polym. Degrad. Stab. 1997, 58, 193-202. [CrossRef]

56. Holdsworth, A.F.; Horrocks, A.R.; Kandola, B.K.; Price, D. The Potential of Metal Oxalates as Novel Flame Retardants and Synergists for Engineering Polymers. Polym. Degrad. Stab. 2014, 110, 290-297. [CrossRef]

57. Holdsworth, A.F.; Horrocks, A.R.; Kandola, B.K. Synthesis and thermal analytical screening of metal complexes as potential novel fire retardants in polyamide 6.6. Polym. Degrad. Stab. 2017, 144, 420-433. [CrossRef]

58. Holdsworth, A.F. Novel Metal Complex Fire Retardants for Engineering Polymers. Ph.D. Thesis, University of Bolton, Bolton, UK, 2015.

59. Salles, V.; Bernard, S.; Brioude, A.; Cornu, D.; Miele, P. A new class of boron nitride fibers with tunable properties by combining an electrospinning process and the polymer-derived ceramics route. Nanoscale 2010, 2, 215-217. [CrossRef]

60. Edmonds, I.; Love, C.E.; Harvey, T. Effects of Gamma Irradiation on the Molecular and Physical Detection Properties of Bacillus Spores. J. Bioterror. Biodef. 2018, 9, 158. [CrossRef]

61. Nagaishi, R.; Jiang, P.Y.; Katsumura, Y.; Domae, M.; Ishigure, K. Radiolysis of Concentrated Nitric Acid Solutions. In Proceedings of the 6th Japan-China Bilateral Symphosium on Radiation Chemistry, Waseda University, Tokyo, Japan, 6-11 November 1994.

62. Nagaishi, R. A model for radiolysis of nitric acid and its application to the radiation chemistry of uranium ion in nitric acid medium. Radiat. Phys. Chem. 2001, 60, 369-375. [CrossRef]

63. IAEA Nuclear Data. Available online: https://www-nds.iaea.org/wimsd/fpyield.htm (accessed on 15 April 2018).

(C) 2019 by the authors. Licensee MDPI, Basel, Switzerland. This article is an open access article distributed under the terms and conditions of the Creative Commons Attribution (CC BY) license (http://creativecommons.org/licenses/by/4.0/). 